\title{
Aplikasi Sensor Passive Infra-Red (PIR) untuk Meningkatkan Keselamatan Pekerja pada Mesin-Mesin Produksi Industri
}

\author{
Joni Welman Simatupang ${ }^{1}$, Indra Sucipta ${ }^{2}$, Azis Wibowo ${ }^{3}$, Kuncoro ${ }^{4}$, dan Yosua Siringoringo ${ }^{5}$ \\ 1,2,3,4,5) Faculty of Engineering, Electrical Engineering Study Program, President University \\ Jl. Ki Hajar Dewantara \\ Kota Jababeka,Cikarang, Bekasi - Indonesia 17550 \\ Email: joniwsmtp@president.ac.id, indrasucipta1@gmail.com, azizwibowolfc@gmail.com, \\ adikuncoro40@gmail.com, yosuacaya@gmail.com
}

\begin{abstract}
This research of literature study discusses about the function and application of infrared sensor-based motion detection devices for work safety on industrial cam machinery. This device was designed to assist the industry in preventing the work accidents that occur due to hazardous industrial machinery. The detector uses a PIR (Passive Infra-Red) sensor as a motion detector of the human limbs. On its application, PIR sensor is placed on a specific side of the machine. Then, the system will provide an automatic cut-off alarms on the machine when a person crosses the fabric area that has been detected by the sensor. It was expected that this way will protect the manpower from the occurrence of work accidents which are caused by dangerous industrial machines. With the implementation of this infrared sensor design, the analysis of hazardous machinery is becoming increased so that this infrared sensor based working security system is growing and easier for shaping in many designs.
\end{abstract}

Keywords: Motion detection devices, PIR sensor, Cam machinery, Cut-off alarm, Sensor design.

\section{ABSTRAK}

Penelitian (studi literatur) ini membahas tentang fungsi dan penerapan dari alat pendeteksi (detektor) gerak berbasis sensor inframerah untuk keselamatan pekerja ketika menggunakan mesinmesin industri. Sensor ini didesain untuk membantu perindustrian dalam mencegah kecelakaan kerja yang mungkin terjadi akibat mesin industri yang berbahaya. Detektor ini menggunakan sensor inframerah pasif atau PIR (Passive Infra-Red) sebagai pendeteksi gerakan dari anggota tubuh manusia. Dalam implementasinya, sensor PIR biasanya dipasang pada sisi tertentu di bagian mesin. Kemudian, sistem tersebut akan memberikan alarm cut-off secara otomatis pada mesin ketika seseorang melintasi area perambahan yang telah terdeteksi oleh sensor. Tentu saja hal ini dapat melindungi manusia dari terjadinya kecelakaan kerja yang diakibatkan oleh mesin industri yang berbahaya. Dengan adanya penerapan desain sensor inframerah ini, maka analisa terhadap mesinmesin berbahaya menjadi semakin meningkat sehingga sistem keamanan kerja berbasis sensor inframerah akan semakin berkembang dan akan memberikan keluwesan (fleksibilitas) hadirnya sensor-sensor sejenis dalam banyak desain.

Keywords: Divais pendeteksi gerak, Sensor PIR, Mesin produksi, Batas tanda bahaya, Desain sensor.

\section{Pendahuluan}

Selama dua dekade terakhir, para peneliti telah mengeksplorasi berbagai teknologi dan metodologi dengan menggunakan (memanfaatkan) sensor dalam berbagai aplikasi termasuk untuk security (keamanan) (Rangkuti, \& Simatupang, 2015; lihat juga Simatupang, Andrian, Zhuang, \& Prasetyo, 2019). early warning detection system (sistem deteksi dini) Simatupang, J.W., Naufal, F., 2019; lihat juga Galina, M., Ramadhani, M.W., Simatupang, J.W., (2019); Saifullana, Simatupang, J.W., 2019), transpotation (transportasi) (Suhartomo,. Simatupang, Widjaja, \& Gapsari, 2018), Internet of Things (IoT) (Ginting, Simatupang, Bukhori, \& Kaburuan, 2018; lihat juga Gunawan, 2017), serta untuk meningkatkan keselamatan pekerja di dunia industri (human safety in industrial world) Cooper, 2001; lihat juga Ulang, Salim, Baharum, F. \& Agus Salim, 2014; Rathnayake, \& Karunasena, 2016; Rosita, Wibowo, Rahayu, 2018). Pemanfaatan teknologi yang dilakukan terutama berfokus pada pendeteksian parameter-parameter tertentu dengan 
menggunakan sensor. Sensor kemudian mengaktifkan peringatan berupa bunyi alarm (buzzer) atau sistem pemberhentian kerja mesin secara otomatis (automatic early warning detection system).

Sampai saat ini, telah banyak perusahaan yang mengeksplorasi penggunaan sistem keselamatan kerja berbasis sensor inframerah (IR sensor). Namun masih banyak juga yang belum menerapkannya sesuai standar yang ditetapkan pemerintah terkait keselamatan kerja, terutama pada perusahaanperusahaan yang baru berdiri. Tulisan ini adalah hasil dari penelitian yang mencoba menganalisis tentang fungsi dan penerapan sistem keselamatan kerja dengan aplikasi teknologi berbasis sensor inframerah pada mesin-mesin industri yang belum mempunyai sistem keselamatan sesuai dengan standar yang seharusnya. Harapannya adalah agar sistem ini bisa diterapkan secara praktis sehingga menghindari kerugian di pihak perusahaan/industri, baik secara fisik maupun materi (Firmandhani, 2016)

Inframerah adalah bagian, atau "pita" cahaya tak terlihat yang ditemukan pada spektrum elektromagnetik. Ini adalah bentuk radiasi panas yang juga bisa disebut "energi inframerah." Di dunia industri, inframerah juga sering digunakan sebagai alat pendeteksi benda (secara esensial fungsinya sebagai sumber cahaya dan sensor di bidang telekomunikasi dan biomedik). Detektor inframerah bekerja dengan prinsip pantulan (reflectivity): sensor mengirimkan sinyal ke sebuah benda (light transmission), maka sebagian dari cahaya yang diserap itu akan dipantulkan kembali ke sensor inframerah dengan panjang gelombang tertentu, dan juga tergantung pada suhu benda tersebut. Pantulan sinyal tersebut akan ditangkap oleh sensor melalui divais detektor cahaya atau light-receiver (Lestari, 2012).

\subsection{Rumusan Masalah}

Rumusan masalah penelitian ini menanyakan bagaimanakah bentuk/model rancangan purwarupa (prototipe) desain sensor inframerah yang baik dan praktis untuk dapat diterapkan pada area produksi, terutama agar dapat dipasang pada mesin-mesin produksi yang memiliki proses-proses atau alat-alat berbahaya di dalamnya seperti: mesin pemotong, mesin penjepit, mesin bor (pembuat lubang), dll.

\subsection{Batasan Masalah}

1) Sistem mengunakan modul utama inframerah pasif sebagai sensor deteksi.

2) Pembuatan sistem harus sesuai dengan data lapangan secara detail demi mendapatkan hasil maksimal dalam meminimalisir terjadinya kecelakaan kerja.

\subsection{Tujuan Penelitian}

Penelitian ini bertujuan untuk memperkenalkan desain prototipe divais sensor berbasis inframerah pasif untuk memantau dan memberi informasi ke mesin. Jika ada indikasi tangan atau bagian tubuh manusia terkena batas sensor inframerah pasif, maka sensor akan mengirim pesan ke mesin untuk standby. Hasil analisa dari penelitian dapat dipakai sebagai dasar/alasan untuk menyediakan sebuah desain sistem keselamatan kerja secara detail yang telah disesuaikan dengan data observasi lapangan. Dengan harapan desain selanjutnya bisa diaplikasikan langsung menjadi alat yang dapat diterapkan langsung di area produksi sebagai sistem keselamatan kerja.

\section{Metode: Disain dan Implementasi}

\subsection{Passive Infra-Red (PIR) Sensor}

Pada dasarnya sensor gerak PIR dan sensor LED inframerah memiliki karakteristik yang sama. Hanya, letak perbedaannya pada modul masing-masing sensor. Sistem sensor infra merah menggunakan infra merah sebagai media komunikasi data antara penerima dan pemancar. Sistem akan bekerja jika sinar infra merah yang dipancarkan terhalang oleh suatu benda yang mengakibatkan sinar infra merah tersebut tidak dapat terdeteksi oleh penerima (Sijabat, 2019; lihat juga Yusniati, 2018). Sedangkan sensor PIR digunakan untuk mendeteksi adanya pancaran sinar infra merah. Sensor PIR ini bersifat pasif, artinya sensor ini tidak memancarkan sinar infra merah 
tetapi hanya menerima radiasi sinar infra merah dari benda lain (Desmira, Nugroho, \& Sutarti, 2020). Bentuk komponen dari sensor PIR ditunjukkan pada Gambar 1.

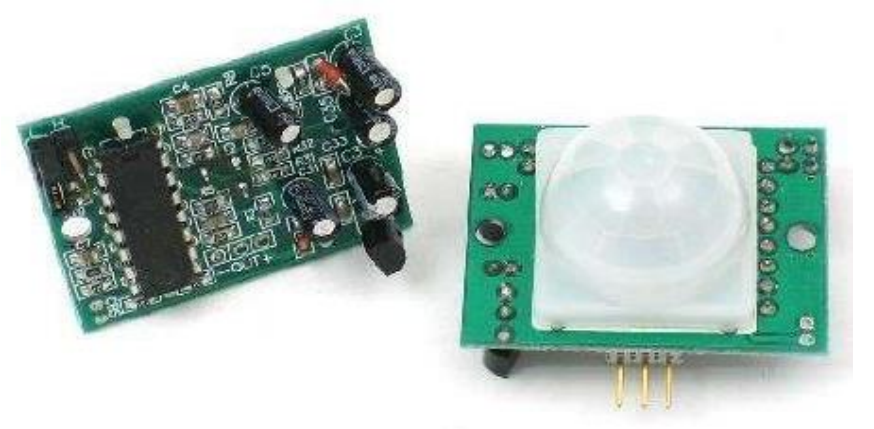

Gambar 1. Bentuk Komponen Sensor PIR (Desmira, Nugroho, \& Sutarti, 2020).

Modul sensor gerak PIR memiliki keluaran yang langsung bisa dihubungkan dengan komponen digital TTL (Transistor-Transistor Logic, tegangan dari $4.75 \mathrm{~s} / \mathrm{d} 5.25 \mathrm{~V}$ ) atau CMOS (Complementary MetalOxide Semiconductor, tegangan dari $0 \mathrm{~s} / \mathrm{d} 0.33 \mathrm{VDD}$ pada level rendah dan 0.67 VDD pada level tinggi) dan juga mikrokontroler. Hasil deteksi kerja dari sensor gerak ini akan menjadi efektif tergantung kepada lokasi/posisi pendeteksiannya. Sensor gerak harus diletakkan pada posisi/lokasi yang tepat sehingga semua gerakan yang ada dalam ruangan dapat terdeteksi/termonitor. Jadi, sangat perlu diatur supaya daerah yang dapat dimonitor tersebut terjangkau oleh sensor atau sesuai dengan jarak yang diinginkan user.

\subsection{Blok Diagram Sensor PIR (Cut Off Mesin)}

Sensor Passive Infra-Red (PIR), seperti nama yang diberikan (*passive) hanya memberikan respons sinyal (energi) dari pancaran sinar inframerah pasif yang dimiliki oleh setiap benda yang terdeteksi olehnya. Umumnya adalah gerakan tubuh manusia. Dan sensor ini memiliki lima bagian utama, yakni lensa Fresnel (Fresnel Lens), penyaring infrared (IR Filter), pendeteksi piroelektrik (Pyroelectric sensor), dan penguat (amplifier), dan pembanding (comparator) seperti terlihat di Gambar 2.

Gambar 2 menunjukkan blok diagram sensor PIR yang bekerja dengan menangkap energi panas yang dihasilkan dari pancaran sinar inframerah pasif yang muncul dari setiap benda dengan suhu di atas 273K, di mana suhu rata-rata tubuh manusia adalah 305K (Universitas Gajah Mada Yogyakarta, 2016).Pancaran sinar inframerah inilah yang kemudian ditangkap oleh pendeteksi piroelektrik yang merupakan bagian inti dari sensor PIR ini sehingga menyebabkan pendeteksi piroelektrik yang terdiri dari gallium nitride $(\mathrm{GaAs})$, cesium nitrate $\left(\mathrm{C}_{5} \mathrm{NO}_{3}\right)$ dan lithium tantalate $(\mathrm{LiTaO})$ memproduksi arus listrik. Jadi, ketika sensor dilewati oleh seseorang, misalnya, maka lensa Fresnel akan memfokuskan energi thermal (panas) yang diterima dan kemudian sensor akan menangkap sinar inframerah pasif yang terpancar dari tubuh orang tersebut. Notabene, suhu tubuh orang tersebut berbeda dengan suhu lingkungan sehingga menyebabkan bahan piroelektrik bereaksi dan menghasilkan arus listrik karena energi panas yang dibawa oleh sinar inframerah pasif. Arus listrik yang dihasilkan kemudian diperkuat oleh divais penguat (amplifier) dan dibandingkan oleh divais pembanding (comparator) sebelum keluar Desmira, Nugroho, \& Sutarti, 2020).

Skematik rangkaian sensor PIR ditunjukkan pada Gambar 3 (Universitas Gajah Mada Yogyakarta, 2016). Mekanisme kerja dari skematik rangkaian tersebut bisa dijelaskan demikian: Pada saat tidak ada energi thermal (panas) yang terdeteksi, maka output sensor akan bernilai 5V dan pnp transistor 'tidak bekerja'. Pada kondisi ini, emitter voltage (e) akan bernilai OV sehingga tegangan npn transistor tidak aktif. Namun, saat ada energi panas yang terdeteksi, maka output sensor menjadi $0 \mathrm{~V}$, pnp transistor aktif, collector voltage (c) mendekati $5 \mathrm{~V}$, mengaktifkan npn transitor sebagai saklar untuk relay dan relay on. DI-PIR Motion Detector adalah modul sensor yang memiliki data keluaran 1 bit, logika " 0 " dan logika "1". Keluaran akan memiliki logika "0" ketika ada perubahan kondisi penyulut (trigger) yang terdeteksi. Penyulut (trigger) yang dimaksudkan adalah motion atau pergerakan tubuh manusia. 


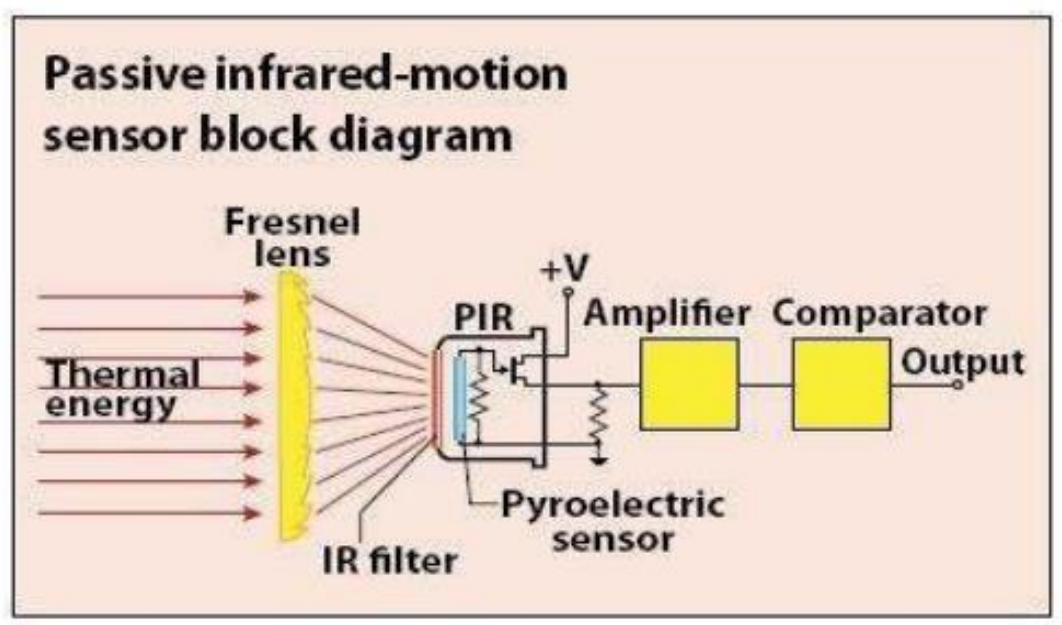

Gambar 2. Blok diagram dari lima komponen utama sensor PIR (Desmira, Nugroho, \& Sutarti, 2020).

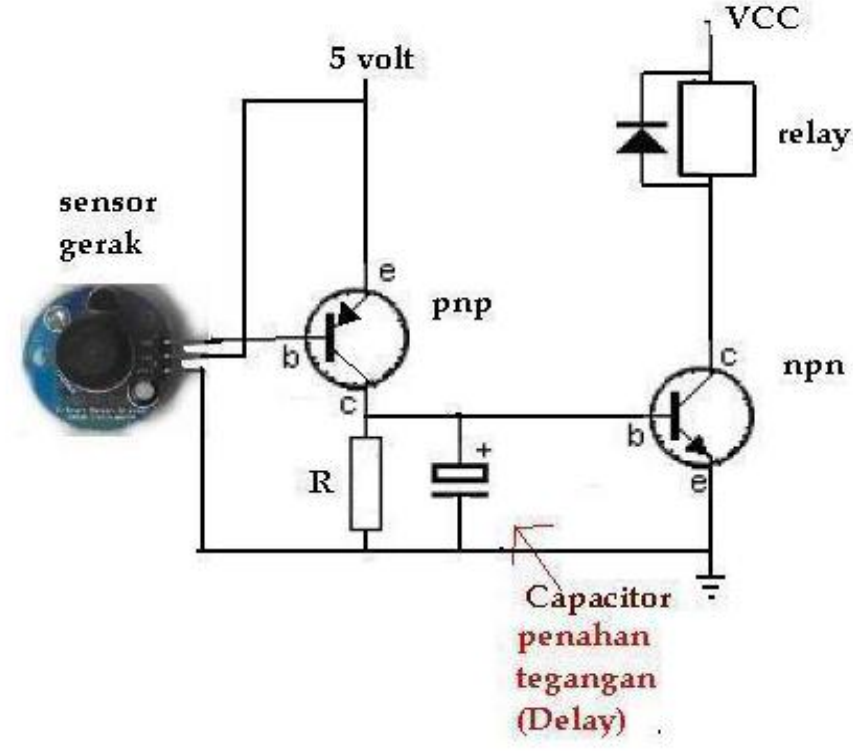

Gambar 3. Skematik Rangkaian Sensor PIR (Astuti, 2010)

Rangkaian cut-off ini (Gambar 3) difungsikan di area-area mesin terutama pada bagian mesin yang mengoperasikan alat-alat berbahaya yang tajam yang dapat melukai manusia. Rangkaian ini memberikan alarm cut-off otomatis pada mesin ketika seseorang melintasi area perambahan yang telah terdeteksi oleh sensor. Hal ini dapat melindungi manpower dari terjadinya kecelakaan kerja.

Gambar 4 berikut menunjukkan blok diagram kerja sensor PIR dengan mesin industri. Penjelasan fungsi blok diagram sebagai berikut:

1. Area deteksi manusia akan terbaca oleh sensor pasif inframerah.

2. Ketika sensor pasif inframerah mendeteksi adanya gerakan dari objek, sensor tersebut akan mengaktifkan fungsi sesuai perintah dari instalasi.

3. Sesuai dengan perintah dari instalasinya, mesin akan off secara otomatis. 


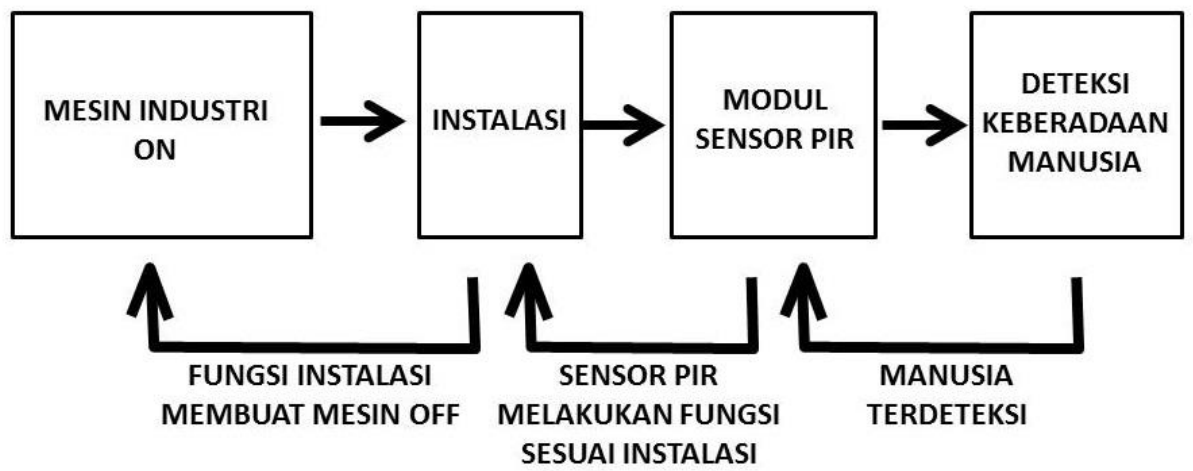

Gambar 4. Blok Diagram Sensor PIR sebagai Cut Off Mesin.

Pada pengaplikasian di atas, sensor PIR digambarkan telah dipasang pada sisi tertentu bagian mesin. Area pendeteksi berwarna biru adalah area yang memungkinkan adanya proses kerja yang berbahaya (Gambar 5), misalnya proses cutting, molding, welding, stamping, dll. Garis strip hitam adalah batasan di mana apabila anggota tubuh manusia melewati batas tersebut maka fungsi cutoff pada mesin akan berfungsi.

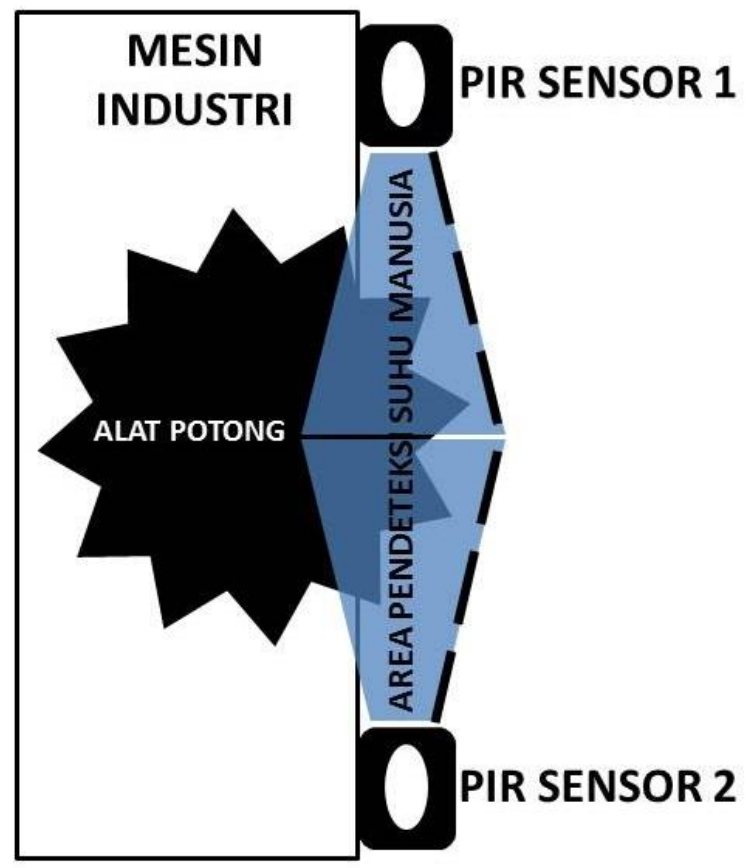

Gambar 5. Area deteksi Sensor PIR pada mesin industri.

\section{Analisa Kelebihan dan Kekurangan}

Untuk melakukan pembuatan alat sesuai dengan kebutuhan lapangan maka akan banyak dibutuhkan data riset yang lebih dalam. Salah satunya adalah untuk mengetahui instalasi yang sebenarnya tentang bagaimana cara menghubungkan modul sensor PIR dengan sistem cut-off mesin agar berfungsi dengan baik. Dikarenakan oleh hasil pengolahan data riset belum dilakukan secara praktik di lapangan (dengan membuat alat/prototipe), maka kami hanya dapat memprediksi kelebihan dan kekurangan dari alat tersebut jika nanti telah diimplementasikan.

Adapun yang menjadi kelebihannya adalah bahwa sensor PIR ini dapat membantu mencegah kecelakaan kerja dengan respon yang sangat cepat dibandingkan dengan modul inframerah biasa, 
ketika akan terjadi kecelakaan kerja. Sedangkan yang menjadi kekurangannya adalah bahwa sensor ini hanya berfungsi ketika cut-off bersifat menghentikan pergerakan mesin secara penuh (menghentikan gerakan benda tajam pada mesin). Jika fungsi cut-off tidak menghentikan fungsi mesin secara penuh, maka akan terjadi kemungkinan akibat dari sisa aktivitas mesin seperti gerakan benda tajam yang masih berjalan secara manual sehingga bisa mencelakai manpower. Untuk mengantisipasinya maka dibutuhkan rangkaian tambahan semacam sistem pengereman atau pemberhentian fungsi mesin secara penuh.

\section{Kesimpulan}

Sistem pengaman dengan sensor pasif inframerah (PIR) dapat mencegah terjadinya kecelakaan kerja dengan respon yang cukup baik sehingga efektif untuk digunakan. Dengan adanya penerapan desain modul sensor PIR ini, maka analisa terhadap mesin-mesin berbahaya menjadi semakin meningkat sehingga sistem keamanan kerja berbasis sensor inframerah akan semakin berkembang dan lebih mudah dibentuk dalam banyak desain. Diharapkan, desain kami ini boleh menambah khazanah pengetahuan dan aplikasi dari sensor ini untuk keselamatan kerja di mesin-mesin industri sekarang.

\section{Daftar Pustaka}

1. Astuti, N.W., (2010). Sistem Keamanan Ruangan Menggunakan Sensor Passive InfraRed (Pir) Kc7783r Dengan Mikrokontroler AT89s51, Laporan Tugas Akhir, Universitas Diponegoro Semarang.

2. Cooper, D. (2001). Improving Safety Culture: A Practical Guide, Applied Behavioural Sciences, John Wiley \& Sons Ltd.

3. Desmira, D.A., Nugroho, W.D. dan Sutarti, (2020). Penerapan sensor passive infrared (PIR) pada Pintu Otomatis di PT LG Electronic Indonesia, Jurnal PROSISKO Vol. 7(1), pp. 1-7.

4. Galina, M., Ramadhani, M.W., and Simatupang, J.W., (2019). Prototype of Postpaid Electricity and Water Usage Monitoring System, International Conference on Sustainable Engineering and Creative Computing (ICSECC), IEEE, pp.304-308, 2019, Bandung, Indonesia.

5. Firmandhani, A., (2016). Gambaran Potensi Bahaya di Bagian Produksi PT. Gemilang Lestari Teknindokabupaten Tegal, Program Skripsi Jurusan Ilmu Kesehatan Masyarakat, Fakultas Ilmu Keolahragaan, Universitas Negeri Semarang.

6. Ginting, S., Simatupang, J.W., Bukhori, I., and Kaburuan, E.R., (2018). Monitoring of Electrical Output Power-Based Internet of Things for Micro-Hydro Power Plant, International Conference on Orange Technologies (ICOT), IEEE, pp.1-7.

7. Gunawan, B.B., (2017). Online Motorcycle Taxi Emergency and Accident Assisting Social IoT Platform, Undergraduate-Thesis, President University.

8. Makalah Sensor Gerak, Universitas Gajah Mada Yogyakarta. (2016). Diambil dari studocu.com/id/document/universitas-gadjah-mada/elektronika/summaries/makalah-sensorgerak/3678472/view.

9. Lestari, K.I., (2012). Rancang Bangun Sistem Parkir Otomatis, Laporan Tugas Akhir, STT Telematika Telkom Purwokerto.

10. Rangkuti, HA., and Simatupang, J.W., (2015). Security Lock with DTMF Polyphonic Tone Sensor, International Conference on Automation, Cognitive Science, Optics, Micro ElectroMechanical System, and Information Technology (ICACOMIT), IEEE, pp.119-122, Bandung, Indonesia.

11. Rathnayake, U and Karunasena, G., (2016). Review of Strategies To Improve Workplace Safety Through Ethical Climates, The $5^{\text {th }}$ World Construction Symposium, Greening Environment, Eco Innovations \& Entrepreneurship, 29-31 July, Colombo, Sri Lanka.

12. Rosita, A. Wibowo, L.A. Rahayu, A. (2018). The Improvement Effort for Safety Awareness Through Integrated Safety Management, Advances in Economics, Business and Management Research, Vol. 117, pp.269-274.

13. Saifullana, and Simatupang, J.W., (2019). Sistem Pendeteksi Kebakaran Rumah Terintegrasi Smartphone dan Aplikasi Online, Journal of Electrical and Electronics (JREC), 6(2), pp.91-98

14. Sijabat, J.B. 2019. Sistem Pembuka dan Menutup Pintu Secara Otomatis dengan Sensor Gerak PIR Berbasis Mikrokontroler ATMega 8535. Repositori Institusi Universitas Sumatera Utara.

15. Simatupang, J.W., Andrian, L.M., Zhuang, W., and Prasetyo, H., (2019). A Prototype of an Arduino-Based Protection System to Overcome Voltage Fluctuations. International Conference on Computer, Control, Informatics and its Applications (IC3INA), IEEE, pp. 172-176, Tangerang, Indonesia. 
16. Simatupang, J.W., and Naufal, F.,(2019). Flood Early Warning Detection System Prototype Based on loT Network, 2019. Internetworking Indonesia Journal (1), pp.17-22.

17. Suhartomo, A., Simatupang, J,W., Widjaja, B., and Gapsari, F., (2018). Feasibility Study on Structural Health Monitoring Systems Using Fiber-Optic Sensors (FOS) Technology for Transportation Infrastructures in Indonesia, International Conference on Mechanical Engineering Research and Application (ICOMERA), Brawijaya University, published in IOP Conference Series: Materials Science and Engineering, Vol.494, pp.1-12, 2019.

18. Ulang, N. Md, Salim, N. S., Baharum, F., and Agus Salim, N.A. (2014) Construction Site Workers' Awareness on Using Safety Equipment: Case Study, MATEC Web of Conferences, 15, EDP Sciences.

19. Yusniati,(2018). Penggunaan Sensor Infrared Switching Pada Motor DC Satu Phasa, Journal of Electrical Technology, Vol.3 (2), pp.90-96. 